\title{
Fibular Hemimelia and Tracheo-Esophageal Fistula in Anewborn in Fallujah General Hospital: A Case Report
}

\author{
Samira T. Abdulghani Alaani ${ }^{1}$, Abdulqadir Abdulkareem Alrawi ${ }^{2}$ \\ ${ }^{1}$ MB. CH. B. DCH, Central Committee of Birth Defects Registration and Follow up, Fallujah General Hospital, Fallujah, Iraq \\ ${ }^{2}$ MB. CH. B. Clinical Geneticist, Central Committee of Birth Defects Registration and Follow up, Fallujah General Hospital, Fallujah, Iraq
}

Email address:

samiraalaani@hotmail.com (S. T. A. Alaani),abd69k@yahoo.com (A. A. Alrawi)

\section{To cite this article:}

Samira T. Abdulghani Alaani, Abdulqadir Abdulkareem Alrawi. Fibular Hemimelia and Tracheo-Esophageal Fistula in Anewborn in Fallujah General Hospital: A Case Report. Science Journal of Clinical Medicine. Vol. 4, No. 5, 2015, pp. 96-98. doi: 10.11648/j.sjcm.20150405.14

\begin{abstract}
Fibular hemimelia is the congenital absence of the fibula and is the most common congenital absence of long bone of the extrimities. It is arare disorder, it may occur as isolated anomaly or as apart of malformation syndrome. The case was reported because it was the $1^{\text {st }}$ diagnosed and documented case in our hospital and because of the rare association with tracheoesophageal Fistula. Case report: Bilateral fibular hemimelia was reported in male newborn in Fallujah general hospital. Both fibulae were totally absent\& the tibiae showed anterior bowing, both feet showed marked equinovalgus deformity. The bone defect was associated with tracheoesophageal fistula.Conclusion: Our case was considered rare because of it's association with trachea-esophageal fistula, It passed undiagnosed prenataly because there was no antenatal care. Effective plans should be put to raise awareness of the importance and the seriousness of antenatal care and improve facilities of early prenatal detection of congenital anomailies and to follow strict registration system of these anomalies.
\end{abstract}

Keywords: Fibular Hemimelia, Tracheo-Esophageal Fistula, Fallujah General Hospital, Fallujah

\section{Introduction}

Fibular hemimelia is the congenital absence of the fibula and is the most common congenital absence of long bone of the extrimities. Shortening of the extremity is obvious at birth with leg length discrepancy ${ }^{1}$.

The incidence of fibular hemimelia has been estimated to be 5.7 to 20 cases per 1 million births. In most cases, it represents an apparently isolated and sporadic event ${ }^{2}$. However, FH may be part of a malformation syndrome. Even though this is a rare condition, it is the most common malformation among the long bone deficiency disorders ${ }^{3}$.

Fibular hemimelia has a clinical spectrum ranging from mild fibular hypoplasia to fibular aplasia. The complete form is more common than the incomplete form; unilateral involvement is more common than bilateral; and the right side is more commonly affected than the left ${ }^{4}$. Bilateral $\mathrm{FH}$ is seen in approximately one third of cases. In these cases, the tibias are often straight ${ }^{5 .}$ When Fibular hemimelia is unilateral, the right side is more commonly affected, and anterior tibial bowing is usually present ${ }^{6}$. In almost all cases, there is deficiency of the lateral foot rays. Less commonly, there is fibular aplasia with a normal number of toes, but almost never is it associated with polydactyly. It is twice common in male fetuses ${ }^{7}$.

Coventry and Johnsonproposed a classification based upon extent of deformity in associated anomalies, with decreasing prognosis, function, and appearance for each type Type I patients have partial, unilateral absence of tine fibula with little or no bowing of the tibia. The extremity is always shortened. There is little or no deformity of the foot. There are no other obvious congenital anomalies in other parts of the body. Shortening is the most common sign. In Type II tine fibula is completely or almost completely absent. The involvement is unilateral. Tine classical deformity is present, with anterior bowing of the tibia, dimpling of the skin,equinovalgus of the foot, and absence or deformity of the rays and tarsal bones. There is always marked shortening of the extremity. Patients with this type of condition invariably need treatment. The prognosis for function and appearance is relatively poor. Type III includes bilateral deformities or congenital absence of the fibula of Type I or Type II associated with other congenital deformities. This was the largest group in Coventry's series, involving 55.2 per cent ${ }^{8}$. The condition in most of these cases is difficult to correct, and the prognosis for adequate function is poorer than in patients with Type I or type II deformity ${ }^{9}$. 


\section{Case Report}

A 2700 gram male baby, born in Fallujah general hospital by spontaneous vaginal delivery on $28^{\text {th }}$ of October 2009 , at 40 weeks following uneventful pregnancy in anon diabetic, non hypertensive mother, 23 years old living in Fallujah,she is gravida 1, para 1 . She have no history of hypertension or diabetis,no history of any febrile illness, no history of using any teratogenic drug during her pregnancy, there was no history of abortion, no previous family history of any congenital anomaly.There was no history of consanguinity between the parents. There is no history of antenatal care.

On examination : the new born have apgar scores of $5 \& 8$ at 0 \& 5 minutes. His head, face, neck, chest, abdomen\& pelvis are appearantly normal.

On his $2^{\text {nd }}$ day the baby started developing respiratory distress after starting oral feeding. There is bowing of both leg with external deviation of both feet ( equinovalgus deformity). (figure 1)

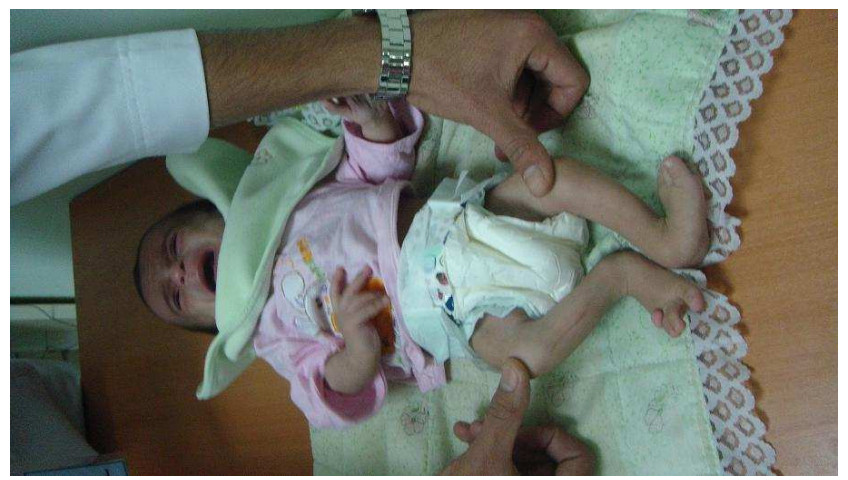

Figure 1.Bowing of both leg with external deviation of both feet.

Routine laboratory work up \& Echocardiography revealed no abonormality.

Barium study revealed presence of Tracheoesophageal fistula.

Radiography showed absence of both fibulae ( bilateral fibular hemimelia), both tibiae were found $\&$ showed anterior bowing, normal pelvis, both femurs, normal upper limbs.(figure 2).

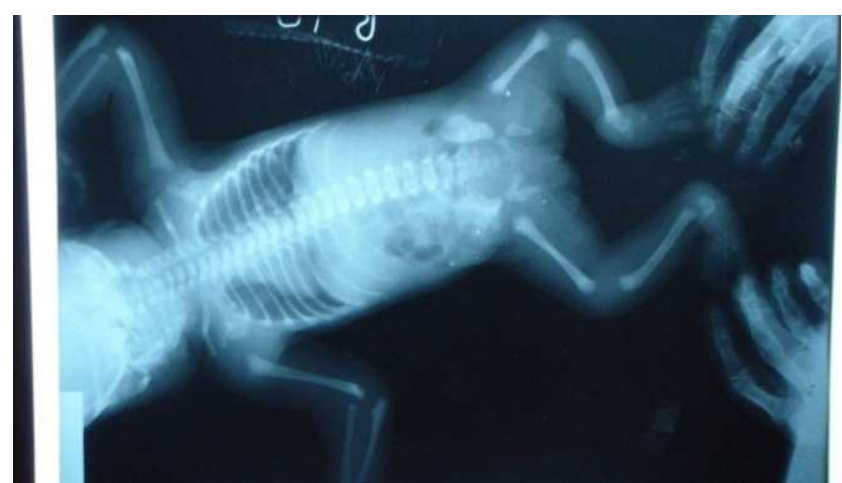

Figure 2.Absence of both fibulae, both tibiae were found with anterior bowing, normal pelvis \&both femurs, normal upper limbs.

\section{Discussion}

Fibular hemimelia was described initially as a condition that is related to aplasia or hypoplasia of the fibula. The precise etiology is unclear ${ }^{9}$. In congenital absence of the fibula the responsible agents must be active before the eighth week of fetal life, as the limb buds usually appear in tile sixth or seventh week. No genetic factor has ever been satisfactorily demonstrated $^{10}$.

Congenital absence of the tibia may be misdiagnosed as congenital absence of the fibula, the differential diagnosis is sometimes most difficult t o make ${ }^{11}$.

In gross appearance important points of differentiation are: (a) the foot and ankle in congenital absence of the tibia are in avarus position and no in valgus. The medial malleolus is missing, with resultant medial displacement of the ankle. (b)While atrophy and shortening of the leg are present, as in congenital absence of the fibula, there is little or no anterior bowing of the leg. (c) There is dislocation at the knee. Without the normal articulation of the tibia on tine femur, the fibula rides laterally and there is no true knee joint ${ }^{12}$. The type of deformity of the foot, as mentioned previously, is of aid, and the fact that tine upper end of the fibula is not broadened and does not actually articulate with the femur helps to distinguish it as a fibula. The bowing, if any, is more lateral than anterior when the tibia is missing ${ }^{13}$.

Our patient's case can be classified within Type 3 group of fibular hemimelia, for being bilateral \& because of it's association with tracheoesophageal fistula. The registration system of congenital anomalies in our hospital is still not precise \& the number of registered cases doesn't represent the actual number present in Fallujah because many cases are usualymissed. This was the $1^{\text {st }}$ reported and documented case in our hospital. According to the fact that there was no history of using any teratogenic drug or material by the mother that cauld contribute to it's occurrence in this baby \& there was no history of consanguinity between the parents, there may be possibility of some relation of environmental pollution to the etiopathogenesis of fibular hemimelia in our patient as this problem has been documented in Fallujah in previous reports ${ }^{14}$ or it may be of sporadic occurrence.

\section{Conclusion}

Our case had several of the typical features of FH, namely, complete bilateral absence of the Fibulae with a bowed tibiae. However, this case was unusual in that the anomaly was associated with trachea-esophageal fistula.

Serious attension should be paid to raise the awareness about the importance of antenatal care, serious \& effective plans should be put to offer and improve the facilities of early prenatal diagnosis and registration system \& follow up of congenital anomalies in Fallujah including those babies born outside the hospital. 


\section{Acknowledgment}

On behalf of ourselves and Fallujah general hospital administration, we would like to extend our thanks and appreciation to Islah reparations represented by Miss Kali Rubaii for covering the publications charges of this paper.

\section{References}

[1] K.C Eze, A.O Akhigbi, G.O.G Awosanya. FIBULAR HEMIMELIA: ACASE REPORT. Nigerian Journal of clinical practice. Sep 2007; Vol (3):259-261.

[2] Florio I, Wisser J, Huch R, Huch A. Prenatal ultrasound diagnosis of a femur-fibula-ulna complex during the first half of pregnancy. Fetal Diagn Ther 1999; 14:310-312

[3] Courtens W, Jespers A, Harrewijn I, Puylaert D, Vanhoenacker F. Fibular aplasia, tibialcampomelia, and oligosyndactyly in a male newborn infant: a case report and review of the literature. American journal of medical genetics Part A. 2005;134 (3):321-25.

[4] Ollerenshaw, Robert. Congenital defects of the long bones of the lower limb. Acontribution to the study of their causes, effects, and treatment. J Bone Joint Surg, July 1925, 7:528-552.

[5] Lewin SO, Opitz JM. Fibular hypoplasia: Review and documentation of the fibular developmental field. Am J Med Genet Suppl 1986; 2:215-238.

[6] O'Rahilly R. Morphological patterns in limb deficiencies and duplications. Am J Anat 1951; 89:135-193.
[7] AS Sidhu MS, HSMann MS, Yashwant Singh Tanwar MS, Arvind Kumar MS, Gursukhman DS Sidhu MBBS: Fibular hemimelia- acase report. Pb Journal of Orthopaedics Vol-XII, No.1, 2010

[8] Meckel, C.: Quoted by Haudek, MAX: IJe-bero'onuge-nuitalen Defect der Fibula unuolole'ss-nu Ve'rinalte'nzursogenanntenintrauterinen Fractur der Tibia. Ze-itschr. f. Orthop. Chir., 1896, 4: 326-401,.

[9] Fordham la, applegateke, wilkes dc, chungcj. Fibular hemimelia: more than just an absent bone. seminmusculoskeletradiol 1999; 3:227-238.

[10] Dr. A. K. Agarwal and Dr. Anil Kumar Gupta. Complete Unilateral Fibular Hemimelia with Polydactyly: A rare case report. Online Journal of Medicine and Medical Science Research ISSN 2277-0879; Volume 2, Issue 7, pp. 82-85; July, 2013.

[11] Bohnewh, root 1. hypoplasia of the fibula. clinorthoprelat res 1977; 107-112.

[12] Jain S, Lakhtakia PK. Profile of congenital transverse deficiencies among case of congenital orthopedic anomalies. J Orthop Surg. (Hong Kong), 2002; 10(1): 45-52.

[13] Dilip L. Lakhkar, Fibular hemimelia: Acase report. VIMS HEALTH SCIENCE JOURNAL ISSN No: 2348-523Xwww.vmshsj.edu.in.

[14] Alaani S, Tafash M, Busby C, HamdanM.Uranium and other contaminants in hair from the parents of children with congenital anomalies in Fallujah, Iraq. Conflict and Health 2011, 5:15. Doi: 10.1186/1752-1505-5-15. 